MICHEL FRANÇOIS DRIZUL HAVRENNE

Regularização Fundiária Rural na Constituição Econômica de 1988

Tese de doutorado

Orientador: Professor Titular Dr. Gilberto Bercovici

UNIVERSIDADE DE SÃO PAULO

FACULDADE DE DIREITO

SÃO PAULO

2017 
MICHEL FRANÇOIS DRIZUL HAVRENNE

\section{Regularização Fundiária Rural na Constituição Econômica de 1988}

Tese apresentada à Banca Examinadora do Programa de Pós-Graduação em Direito, da Faculdade de Direito da Universidade de São Paulo, como exigência parcial para obtenção do título de Doutor em Direito, na área de concentração Direito Econômico, Financeiro e Tributário (DEF), sob a orientação do Professor Titular Dr. Gilberto Bercovici.

UNIVERSIDADE DE SÃO PAULO

FACULDADE DE DIREITO

SÃO PAULO 
Serviço de Processos Técnicos da Biblioteca da Faculdade de Direito da Universidade de São Paulo

HAVRENNE, Michel François Drizul, Regularização Fundiária Rural na Constituição Econômica de 1988 (Orientador: Bercovici, Gilberto), Tese de doutorado em Direito apresentada na Faculdade de Direito da Universidade de São Paulo, São Paulo: 2017, 264 páginas. 
Nome: HAVRENNE, Michel François Drizul

Título: Regularização Fundiária Rural na Constituição Econômica de 1988.

Tese apresentada à Banca Examinadora do Programa de Pós-Graduação em Direito, da Faculdade de Direito da Universidade de São Paulo, como exigência parcial para obtenção do título de Doutor em Direito, na área de concentração Direito Econômico, Financeiro e Tributário (DEF), sob a orientação do Professor Titular Dr. Gilberto Bercovici.

Resultado:

Banca Examinadora: 


\section{Agradecimentos}

Aos meus pais, Julia e Poti, pelo constante incentivo aos estudos.

À minha esposa e à minha filha, Marcela e Maria Fernanda, pela compreensão nas ausências.

Ao meu orientador, Gilberto, pela oportunidade dada, pela orientação segura e pelas excelentes sugestões no decorrer dos trabalhos.

À banca de qualificação, composta pelos Professores André Ramos Tavares e Eneas de Oliveira Matos, pelas críticas oportunas.

Aos colegas da Advocacia-Geral da União, do Instituto Nacional de Colonização e Reforma Agrária e do Ministério Público Federal, pela possibilidade de lidar com o tema da regularização fundiária.

Ao Ministério Público Federal, por ter incentivado a elaboração da presente tese.

A todos aqueles que desejam e lutam por um país mais justo. 


\section{Resumo}

HAVRENNE, Michel François Drizul, Regularização Fundiária Rural na Constituição Econômica de 1988, Tese de doutorado em Direito apresentada na Faculdade de Direito da Universidade de São Paulo, São Paulo: 2017, 264 p.

Este trabalho irá estudar a regularização fundiária rural, como processo indispensável ao desenvolvimento econômico, à preservação ambiental, ao respeito às diversidades étnicas e culturais e à erradicação da pobreza no país. A regularização fundiária insere-se num contexto de reestruturação da ordenação agrária, portanto, abarcada pela reforma agrária. É também política de Estado, tendo em vista que é pressuposto à superação do subdesenvolvimento. Ela é essencial à efetivação da justiça social. Assim, serão analisadas a regularização fundiária 'genérica', a regularização fundiária na Amazônia Legal, a regularização fundiária em faixa de fronteira, a regularização fundiária em unidades de conservação e a regularização fundiária de áreas ocupadas por minorias.

Palavras-chave: regularização fundiária rural, desenvolvimento econômico, preservação ambiental, pluralidade cultural e erradicação da pobreza. 


\section{Abstract}

HAVRENNE, Michel François Drizul, Rural Land Regularization in the 1988 Economic Constitution, P.H.D. Thesis in Law presented at the Faculty of Law of the University of São Paulo, São Paulo: 2017, 264 p.

This thesis aims to study the rural land regularization as an indispensable process for economic development, environmental preservation, respect for ethnic and cultural diversities and the eradication of poverty in the country. Land regularization is part of the restructuring process contained within the rural order, which is covered by farm reform. It is also a state policy, since it acts as a prerequisite for overcoming underdevelopment. It is essential for the accomplishment of social justice. Thus, the regularization of the 'generic' land ownership, of the Legal Amazon, of border areas, conservation units and areas occupied by minorities shall be analyzed in the context of this thesis.

Keywords: rural land regularization, economic development, environmental preservation, cultural plurality and eradication of poverty. 


\section{Riassunto}

HAVRENNE, Michel François Drizul, Regolarizzazione Fondiaria Rurale nella Costituzione Economica del 1988, Tesi di dottorato in Giurisprudenza presentata presso la Facoltà di Giurisprudenza dell'Università di São Paulo, São Paulo: 2017, 264 p.

Questo lavoro analizzerà la regolarizzazione fondiaria rurale, in qualità di processo indispensabile allo sviluppo economico, alla preservazione ambientale, al rispetto delle diversità etniche e culturali ed alla eradicazione della povertà nel Paese. $\mathrm{La}$ regolarizzazione fondiaria si inserisce in un contesto di ristrutturazione dell'ordinamento agrario, quindi, abbracciata dalla riforma agraria. È anche politica di Stato, tenendo presente che è presupposto al superamento del sottosviluppo. È essenziale alla realizzazione della giustizia sociale. Verranno quindi analizzate la regolarizzazione fondiaria "generica", la regolarizzazione fondiaria nell'Amazônia Legal (la parte dell'Amazzonia appartenete al Brasile), la regolarizzazione fondiaria nella fascia di frontiera, la regolarizzazione fondiaria nelle unità di conservazione e la regolarizzazione fondiaria nelle aree occupate da minoranze.

Parole chiave: regolarizzazione fondiaria rurale, sviluppo economico, preservazione ambientale, pluralità culturale ed eradicazione della povertà. 


\section{Lista de Abreviaturas}

ADI- Ação direta de inconstitucionalidade

ADCT- Ato das Disposições Constitucionais Transitórias

AGU- Advocacia-Geral da União

AR- ação rescisória

Art.- artigo

CC- Código Civil

CDN- Conselho de Defesa Nacional

CF- Constituição Federal

CF/88- Constituição da República Federativa do Brasil de 1988

CGA- Coordenação-Geral Agrária da Procuradoria Federal Especializada do Instituto Nacional de Colonização e Reforma Agrária

CNBB- Conferência Nacional dos Bispos do Brasil

DAF-3- Divisão de Administração de Títulos e Cobrança de Créditos do INCRA

DF- Distrito Federal

DNPM- Departamento Nacional de Produção Mineral

EC- Emenda Constitucional

EUA- Estados Unidos da América

FAO- Organização das Nações Unidas para a Alimentação e a Agricultura

FMP- fração mínima de parcelamento

FUNAI- Fundação Nacional do Índio

FUNAD- Fundo Nacional Antidrogas

GEE- grau de eficiência na exploração da terra

GUT- grau de utilização da terra

IBAMA- Instituto Brasileiro do Meio Ambiente e dos Recursos Naturais Renováveis

ICMBIO- Instituto Chico Mendes de Conservação da Biodiversidade

IN- Instrução Normativa

INCRA- Instituto Nacional de Colonização e Reforma Agrária

IPHAN- Instituto do Patrimônio Histórico e Artístico Nacional

IPTU- imposto predial e territorial urbano

ITR- imposto sobre a propriedade territorial rural 
LAF- laudo agronômico de fiscalização

LC- lei complementar

MDA- Ministério do Desenvolvimento Agrário (extinto)

MEI- módulo de exploração indefinida

MPF- Ministério Público Federal

MS- mandado de segurança

MST- Movimento dos Trabalhadores Rurais Sem Terra

OIT- Organização Internacional do Trabalho

PF- pessoa física

PFE- Procuradoria Federal Especializada

PGR- Procuradoria-Geral da República

PJ- pessoa jurídica

PUC- Pontifícia Universidade Católica

RTID- Relatório Técnico de Identificação e Delimitação

SENAD- Secretaria Nacional de Políticas sobre Drogas

SFB- Serviço Florestal Brasileiro

SNCR- Sistema Nacional de Cadastro Rural

SPU- Secretaria de Patrimônio da União

STF- Supremo Tribunal Federal

STJ- Superior Tribunal de Justiça

STN- Secretaria do Tesouro Nacional

TDA- título da dívida agrária

Unicamp- Universidade Estadual de Campinas

USP- Universidade de São Paulo 


\section{Índice}

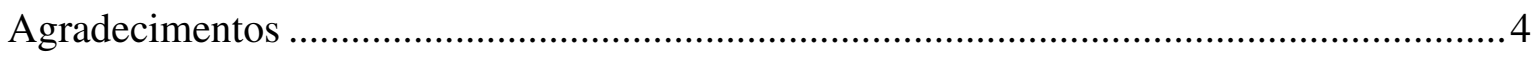

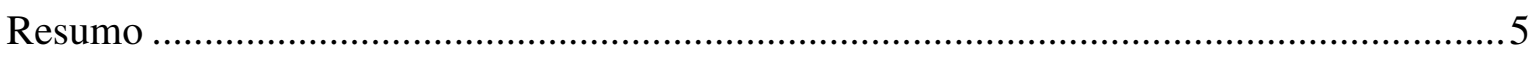

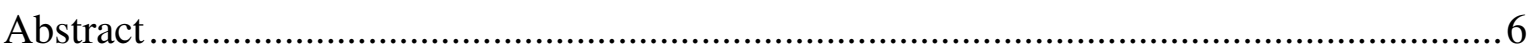

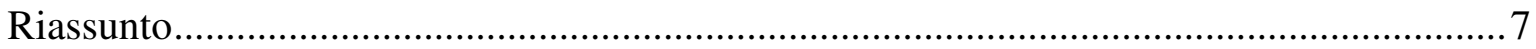

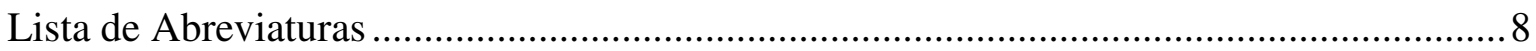

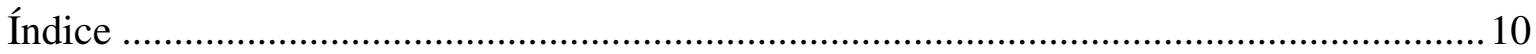

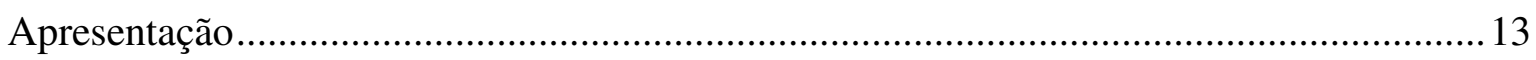

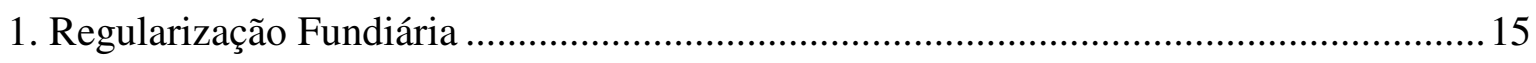

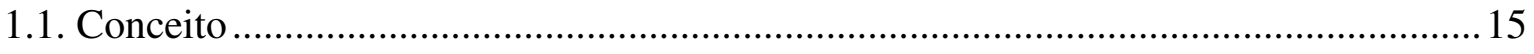

1.2. Bases constitucionais da regularização fundiária ....................................................... 18

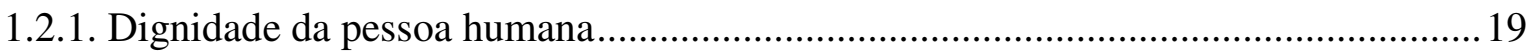

1.2.2. Erradicação da pobreza e da marginalização e redução das desigualdades sociais e

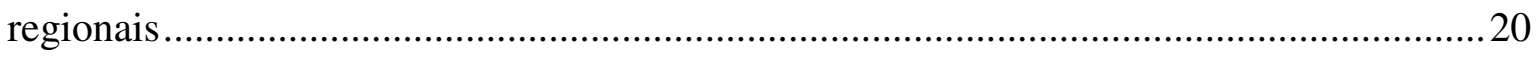

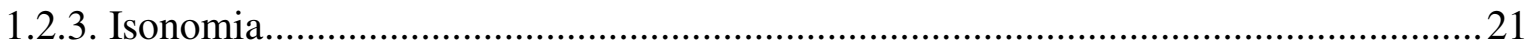

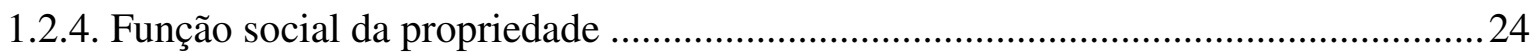

1.2.4.1. Breve histórico constitucional da função social da propriedade .............................24

1.2.4.2. Conteúdo da função social da propriedade ...........................................................28

1.2.4.3. Decorrências da previsão constitucional sobre a função social da propriedade ......33

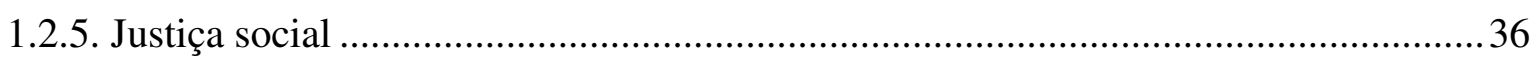

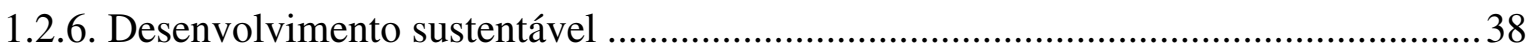

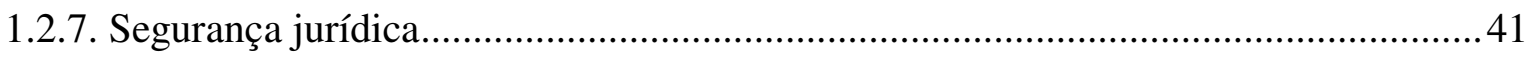

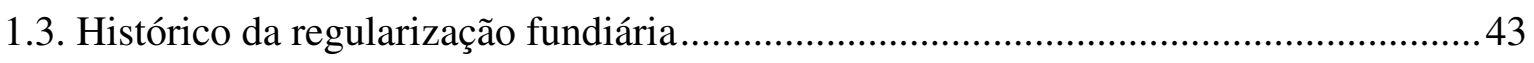

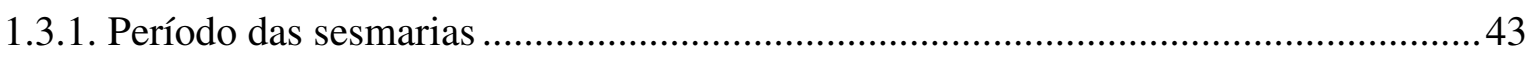

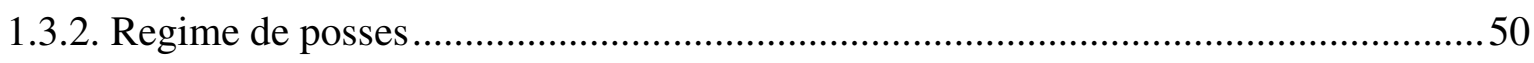

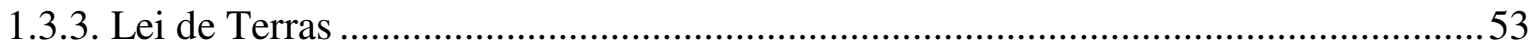

1.4. Principais instrumentos para a regularização fundiária rural........................................57

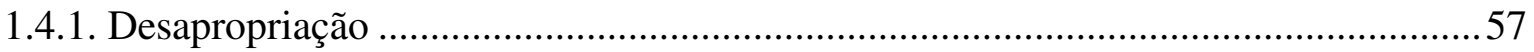

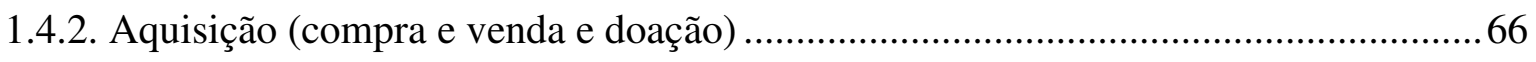

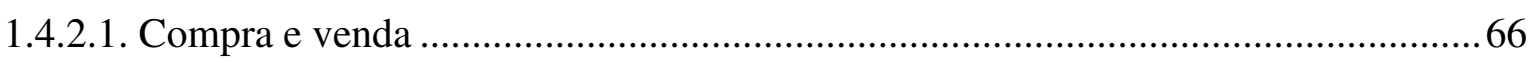


1.4.2.2. Doação

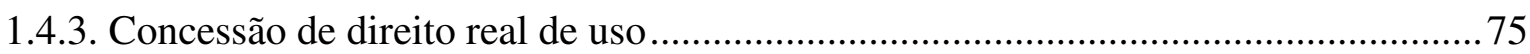

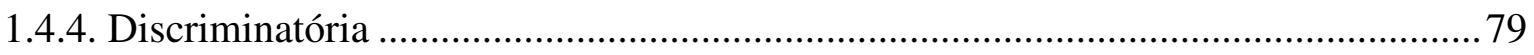

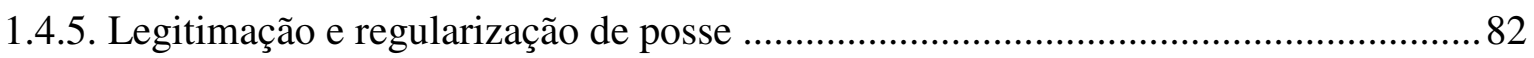

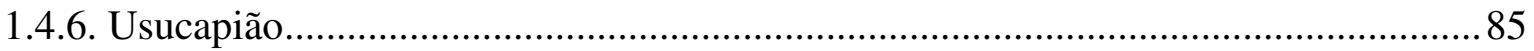

1.5. Regularização fundiária como elemento da reforma agrária ..................................... 87

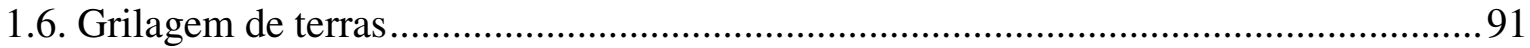

1.7. Regularização fundiária e aquisição de terras por estrangeiros ...................................95

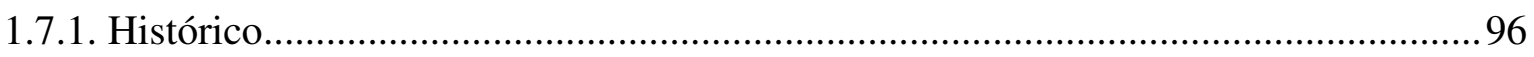

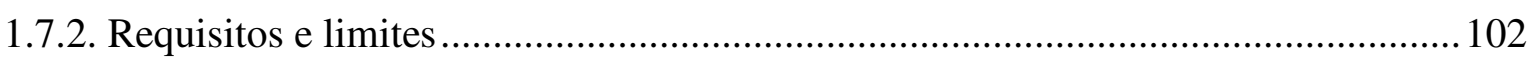

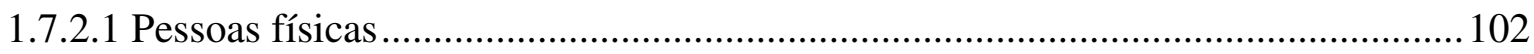

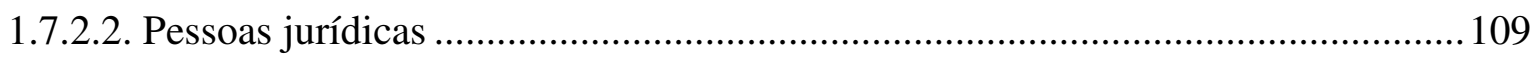

1.7.2.3. Pessoas jurídicas brasileiras controladas por estrangeiros.................................. 112

1.7.3. Convalidação de vícios na aquisição de terras por estrangeiros .............................. 117

1.8. Regularização fundiária como pressuposto ao desenvolvimento econômico-social .. 119

1.9. Planejamento estatal e regularização fundiária......................................................... 122

1.10. Ordem econômica e regularização fundiária ............................................................. 124

1.11. Conclusões sobre a regularização fundiária rural 'genérica' ..................................126

2. Regularização Fundiária na Amazônia Legal ............................................................... 129

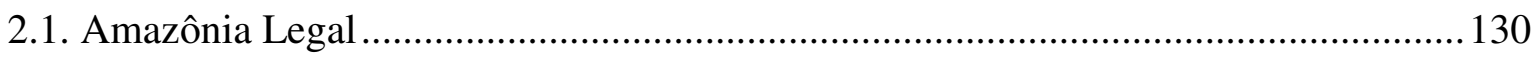

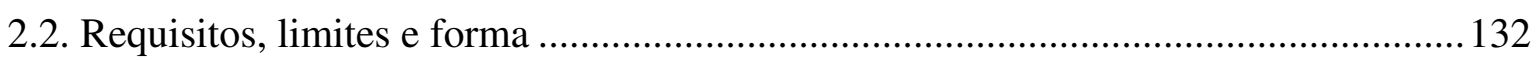

2.3. Política Agrícola, fundiária, reforma agrária e regularização fundiária na Amazônia

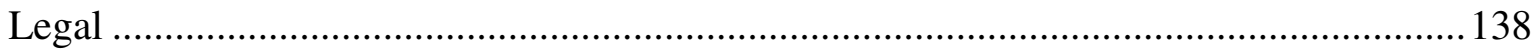

2.4. Discussão sobre a constitucionalidade de dispositivos da Lei $11.952 / 09 . \ldots \ldots \ldots \ldots \ldots . . . . . .140$

2.5. Medida Provisória n $759 / 16$, Projeto de Lei de Conversão no 12/17 e Lei 13.465/17

2.6. Conclusões sobre a regularização fundiária rural na Amazônia Legal....................... 150

3. Regularização Fundiária em Faixa de Fronteira .......................................................... 152

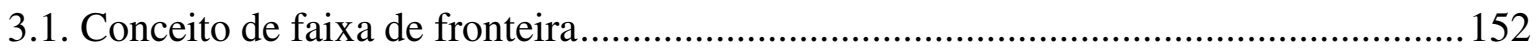

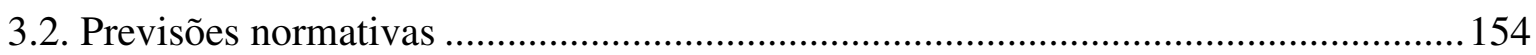

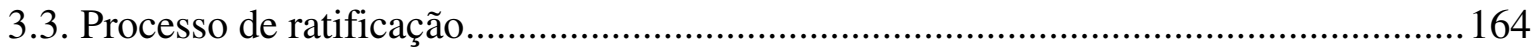

3.3.1. Controvérsias sobre a ratificação (tamanho do imóvel, índices de produtividade e

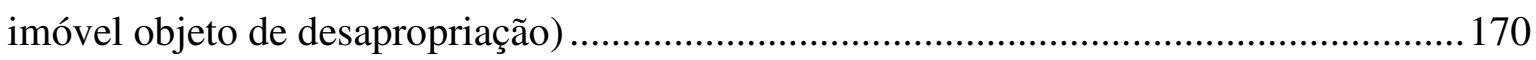

3.4. Faixa de fronteira $\mathrm{x}$ presença de comunidades tradicionais .................................... 175 
3.5. Conclusões sobre a regularização fundiária em faixa de fronteira ............................. 179

4. Regularização Fundiária em Unidades de Conservação ................................................ 181

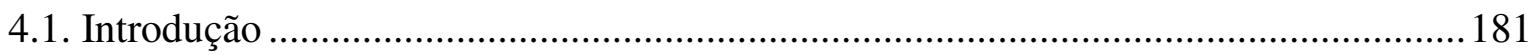

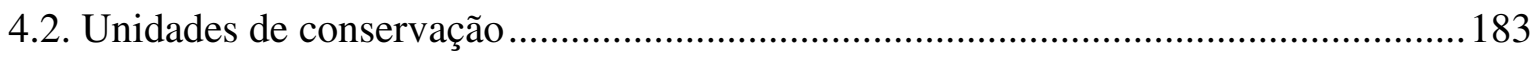

4.2.1. Unidades de Conservação de Proteção Integral.........................................................187

4.2.2. Unidades de Conservação de Uso Sustentável ......................................................... 188

4.3. Princípio da precaução/prevenção ambiental .............................................................. 191

4.4. Princípio da participação e cooperação ambiental...................................................... 193

4.5. Regularização fundiária nos espaços ambientais protegidos .................................... 197

4.6. Proteção ambiental x presença de comunidades tradicionais ..................................... 201

4.7. Conclusões sobre a regularização fundiária em unidades de conservação ..................207

5. Regularização Fundiária em áreas ocupadas por minorias ............................................209

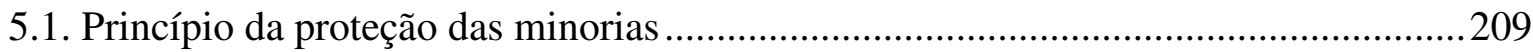

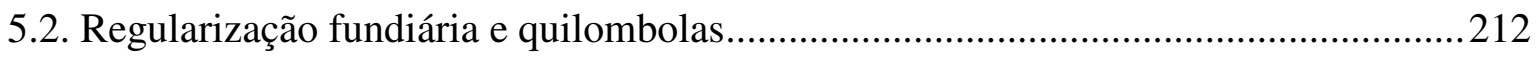

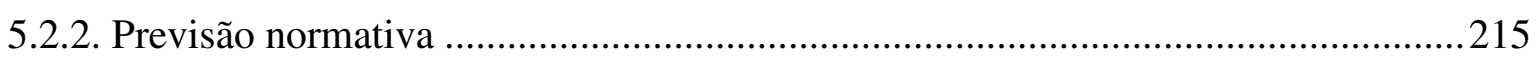

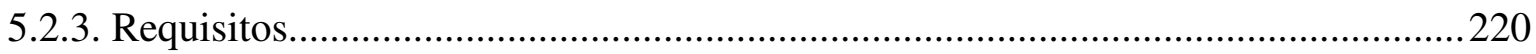

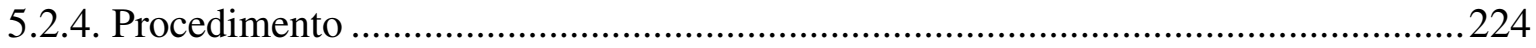

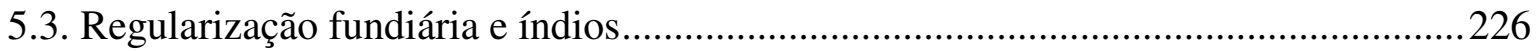

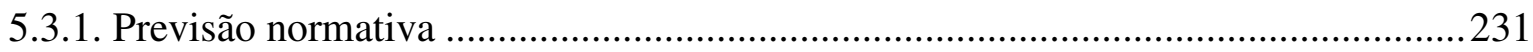

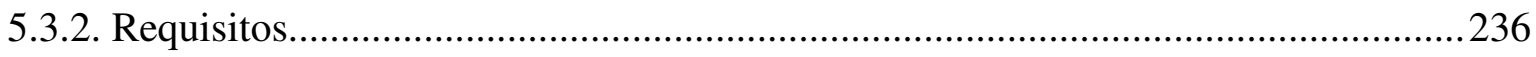

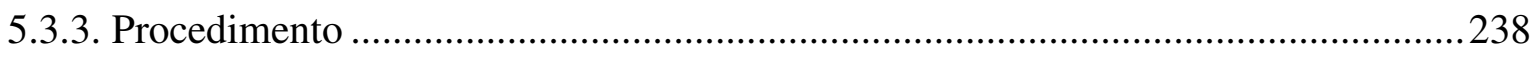

5.4. Conclusões sobre a regularização fundiária de áreas ocupadas por minorias .............241

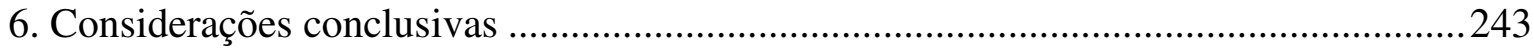

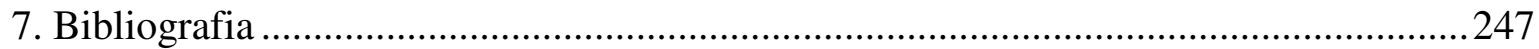

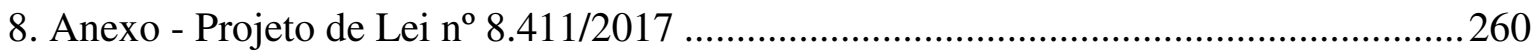




\section{Apresentação}

A presente tese visa estudar a regularização fundiária rural, sob a ótica constitucional, agrária e econômica.

Como principais pontos a serem analisados sobre a regularização fundiária, têm-se:

a) regularização fundiária, e discussão como parte ou não da reforma agrária;

b) regularização fundiária na Amazônia Legal;

c) regularização fundiária em faixa de fronteira, com a ratificação de terras, e diversas previsões constitucionais;

d) regularização fundiária em unidades de conservação;

e) regularização fundiária e minorias;

f) considerações conclusivas acerca da regularização fundiária.

No capítulo 1, serão feitas considerações gerais sobre a regularização fundiária, apresentando-se a sua conceituação, bases constitucionais, histórico de terras no Brasil, principais instrumentos, vínculo com a reforma agrária, grilagem de terras, aquisição de terras pelos estrangeiros, desenvolvimento econômico-social, planejamento estatal e ordem econômica constitucional.

No capítulo 2, serão abordados os requisitos e elementos essenciais da regularização fundiária na Amazônia Legal. Trata-se de região de grandes dimensões e com importância ecológica fundamental. A compatibilização dos diversos interesses envolvidos na área é extremamente complexa. Dessa forma, será feito o estudo da Lei 11.952/09 e suas recentes alterações.

No capítulo 3, irá ser analisada a regularização fundiária em faixa de fronteira. Ela consiste em local indispensável ao país, haja vista que delimita o território nacional. Desta forma, a sua ocupação deve ser feita de forma criteriosa. Tendo em vista a conturbada regulamentação normativa, será analisado o instituto da ratificação de terras. Também, serão apontadas as diversas previsões constitucionais sobre o tema. 
No capítulo 4, será abordada a regularização fundiária em unidades de conservação. Estes espaços especialmente protegidos foram criados com a finalidade de preservar e respeitar o meio ambiente, em razão de suas peculiaridades naturais. Será feita a ponderação entre a preservação ambiental e a manutenção dos povos tradicionais. Ademais, serão analisadas as previsões normativas internacionais, constitucionais e legais.

No capítulo 5, será analisada a regularização fundiária de áreas ocupadas por minorias, dando-se ênfase aos quilombolas e índios. A preservação e o respeito a estes locais guarda consonância com a proteção do patrimônio cultural brasileiro. Há, do mesmo modo, um resguardo do meio ambiente. Serão estudados os compromissos internacionais firmados pelo Brasil, bem como as normas constitucionais e legais sobre o tema.

No capítulo 6, serão realizadas as considerações conclusivas sobre a tese.

Importante, por fim, registrar que o foco desta tese recairá na regularização fundiária rural, e não na urbana. 


\section{Considerações conclusivas}

A regularização fundiária insere-se no escopo maior de promoção da dignidade humana, fundamento da República Federativa do Brasil.

Em sentido abrangente, trata-se de política de Estado para arrecadar terras que descumpram a função social, as quais serão posteriormente destinadas a pessoas com vocação agrícola. Engloba principalmente as terras públicas e devolutas. Em alguns casos, pode abranger terras particulares. Vide os casos em que o Estado deve desapropriá-las, a fim de resguardar o meio ambiente ou o direito das minorias.

Em sentido estrito, a regularização fundiária consiste num conjunto de medidas voltado à titulação de trabalhadores rurais, que produzem alimentos em áreas públicas. O título concedido irá proporcionar o acesso do ocupante a políticas públicas essenciais, como financiamentos agrícolas e programas de incentivo à produção no campo. O seu âmbito restringe-se a terras públicas e devolutas.

Trata-se, em síntese, de um instrumento de reordenação da estrutura fundiária, pela concessão de um título de posse ou propriedade às pessoas que almejam produzir no campo.

Faz parte, portanto, da reforma agrária, que busca a alteração do status quo, por meio da desconcentração de riquezas e da promoção do desenvolvimento social.

Tanto a regularização fundiária, quanto a reforma agrária, possuem conteúdo socioeconômico, estando abarcadas na Constituição Econômica. Ela contempla o conjunto de normas que incidem sobre as atividades econômicas. Estas, por sua vez, não podem ser estudadas, de forma apartada, das normas de conteúdo social.

Logo, tudo o que diz respeito à regularização fundiária insere-se na Constituição Econômica, já que há a conjugação do aspecto econômico (terra como propriedade) com o social (promoção da dignidade humana, preservação do meio ambiente, garantia da defesa nacional e respeito às diferentes culturas).

A CF/88 indica que um dos objetivos da República é a promoção do desenvolvimento nacional (art. $3^{\circ}$, II). 
O Estado, neste contexto, ganha importância, haja vista que, como agente regulador da atividade econômica, tem de planejar ações visando ao desenvolvimento do país (art. 174 da CF).

No tocante à política de terras, o Brasil não pode ficar subordinado a interesses especulativos, sem qualquer vocação para o desenvolvimento nacional.

Há que se quebrar o paradigma patrimonialista. Ele consiste na confusão do público com o privado e na manutenção do poder nas mãos dos afortunados.

A regularização fundiária é uma política que visa justamente romper com tal estrutura de poder.

Diga-se que boa parte dos conflitos fundiários brasileiros remonta ao histórico de ocupação das terras, desde a época do descobrimento.

As concessões de terras, no regime sesmarial, propiciaram a formação de grandes latifúndios. Elas eram destinadas aos poderosos, amigos do rei.

Com a Lei de Terras (Lei 601, de 18 de setembro de 1850), promoveu-se a sua mercantilização. A propriedade passou a ter um cunho predominantemente econômico. Aqueles que possuíam terras, por sua vez, tinham riqueza.

Além disto, a Lei de Terras foi a primeira tentativa de regularização fundiária no país.

No entanto, a confusão legislativa, o excesso de burocracia e a falta de controle das terras pelo Poder Público, proporcionaram o caos fundiário aqui instalado.

Reflexos disto estão em toda a parte: a) na Amazônia; b) nas fronteiras; c) nos espaços territoriais especialmente protegidos; d) nas áreas ocupadas por minorias.

Em relação à Amazônia legal, trata-se um dos locais de maior riqueza ambiental do mundo, compreendendo boa parte do território nacional.

Nela, há uma complexa teia de relações sociais, com a presença de posseiros, índios, empresários, que apresentam interesses contrapostos na sua ocupação.

A regularização fundiária na Amazônia é fundamental para pacificar a região, promover o desenvolvimento social, preservar o meio ambiente e colaborar para o progresso econômico e para a diminuição das desigualdades sociais e regionais. 
No tocante às fronteiras, a sua importância decorre da localização estratégica, que delimita o território nacional. Desta forma, ela é imprescindível à defesa do Brasil.

O emaranhado de normas que se sucederam, a partir de 1850, gerou uma grande confusão fundiária. Houve alteração do tamanho da faixa, bem como de sua titularidade.

Isto causou a concessão de terras por entes que não dispunham de poder para tanto, bem como transferências sem a anuência dos órgãos competentes.

A fim de evitar uma tragédia econômica e social, decorrente da insegurança jurídica, o legislador optou pela possibilidade de ratificação, em certos casos, dos imóveis rurais na faixa de fronteira.

A regularização fundiária na faixa de fronteira é imprescindível para o desenvolvimento do país. Deve focar-se nos pequenos produtores rurais e comunidades locais. Ainda, deve ser compatível com a defesa nacional. Ela irá possibilitar a progressão social de pessoas com vocação agrícola, garantindo os espaços ocupados por populações tradicionais. Também, deve compatibilizar todas estas ocupações com a defesa nacional.

Quanto aos espaços especialmente protegidos, o seu objetivo primordial é a preservação ambiental.

No país, a instalação das unidades de conservação ocorreu sem qualquer planejamento. Foram verificadas inúmeras ocupações humanas em locais que não a comportavam.

Desta forma, o Sistema Nacional de Unidades de Conservação (Lei $n^{\circ}$ 9.985/2000) passou a ser uma peça de ficção, com o desrespeito da CF/88, bem como de diversos diplomas internacionais.

Há, assim, a imprescindibilidade de regularização fundiária das Unidades de Conservação, com a readequação de tais espaços às suas finalidades. Tais espaços são essenciais ao desenvolvimento sustentável do país. Deve-se, ainda, resguardar os direitos de indígenas e de outras populações tradicionais que nelas habitam.

No tocante às áreas ocupadas por minorias, a regularização fundiária tem por escopo garantir a sobrevivência destes grupos. 
Isto decorre do fato de que a terra não tem natureza essencialmente econômica, mas sim de preservação da cultura própria. A relação dos povos tradicionais com a terra não é de cunho patrimonial, mas sim afetivo.

Com a regularização fundiária das minorias, garante-se a diversidade étnica e o respeito às diferenças entre as pessoas.

Tanto a CF/88, como diversos documentos internacionais incorporados no ordenamento pátrio, asseguram às minorias a sua identidade cultural. Esta deve ser analisada com o olhar destes grupos, e não da parcela dominante da sociedade.

Assim, a regularização fundiária de áreas ocupadas por minorias irá promover o respeito à dignidade destes povos tradicionais, tão importantes para a formação do Estado brasileiro. Com isto, a sociedade, como um todo, sai vitoriosa.

A CF/88 dita que devem ser resguardados a dignidade da pessoa humana, erradicação da pobreza, redução das desigualdades sociais e regionais, isonomia, função social da propriedade, justiça social, segurança jurídica e desenvolvimento sustentável. Isto somente poderá ser efetivado com políticas que promovam a melhoria da qualidade de vida de pessoas que almejam colaborar com o país, mas nunca tiveram oportunidade para tanto.

Enfim, a regularização fundiária é pressuposto de superação do subdesenvolvimento, sendo um passo importante para a realização dos direitos fundamentais constitucionais. 


\section{Bibliografia}

ABREU, Capistrano de, Capítulos da história colonial, $7^{\mathrm{a}}$ edição (revisada, anotada e prefaciada por José Honório Rodrigues), Belo Horizonte: Itatiaia; São Paulo: Publifolha, 2000 (Grandes nomes do pensamento brasileiro).

ÁVILA, Humberto. Teoria dos princípios - da definição à aplicação dos princípios jurídicos. 13ª ed., revista e ampliada. São Paulo: Malheiros, 2012.

ATAIIDE JÚNIOR, Wilson Rodrigues, Os direitos humanos e a questão agrária no Brasil- a situação do sudeste do Pará, Brasília: Universidade de Brasília, 2006.

BANDEIRA DE MELLO, Celso Antonio, Conteúdo jurídico do princípio da igualdade, $3^{\mathrm{a}}$ edição, $11^{\mathrm{a}}$ tiragem, São Paulo: Malheiros, 2003.

BARROS, Wellington Pacheco, Curso de Direito Agrário, 6 edição, Porto Alegre: Livraria do Advogado, 2009.

BARROSO, Luís Roberto, Curso de direito constitucional contemporâneo: os conceitos fundamentais e a construção do novo modelo, $2^{\text {a }}$ edição, São Paulo: Saraiva, 2010.

BASTOS, Celso Ribeiro, Curso de Direito Constitucional, 12a edição, São Paulo: Saraiva, 1990.

BEARD, Charles A. e BEARD, Mary R., A basic history of the United States, Philadelphia: The New Home Library, 1944.

BECK, Ulrich, La sociedad del riesgo - hacia una nueva modernidad, Barcelona: Paidós, 2002.

BERCOVICI, Gilberto, A ordem econômica no espaço reforma urbana e reforma agrária na Constituição de 1988, in Revista dos Tribunais, São Paulo, volume 910/2011, agosto de 2011, p. 91-102.

BERCOVICI, Gilberto, Constituição econômica e desenvolvimento - uma leitura a partir da Constituição de 1988, São Paulo: Malheiros, 2005. 
BERCOVICI, Gilberto, Dilemas da concretização da Constituição de 1988, Revista do Instituto de Hermenêutica Jurídica - RIHJ, Belo Horizonte, ano 1, n. 2, jan./dez. 2004.

BERCOVICI, Gilberto, Direito Econômico do Petróleo e dos Recursos Minerais, São Paulo: Quartier Latin, 2011.

BERCOVICI, Gilberto, Função social da propriedade agrária - possibilidade de desapropriação para fins de reforma agrária de propriedade rural que não cumpre todos os requisitos do art. 186 da Constituição de 1988, RTDC, vol. 31, jul/set. 2007.

BERCOVICI, Gilberto, O direito de propriedade e a Constituição de 1988: algumas considerações críticas, Cadernos de Direito, Cadernos do curso de mestrado em direito da Universidade Metodista de Piracicaba, volume 3, $\mathrm{n}^{\mathrm{o}}$ 5, dezembro de 2003.

BERCOVICI, Gilberto, Propriedade que descumpre função social não tem proteção constitucional, disponível em http://www.conjur.com.br/2015-dez-06/estadoeconomia-propriedade-nao-cumpre-funcao-social-nao-protecao-constitucional, acesso em 28/03/2016.

BERCOVICI, Gilberto, Reformas de base e a superação do subdesenvolvimento in Cadernos de Pós-Graduação em Direito, Comissão de PósGraduação da Faculdade de Direito da USP, São Paulo, n. 27, 2014.

BERCOVICI, Gilberto, Soberania e Constituição: Para uma crítica do constitucionalismo, 2 $2^{\mathrm{a}}$ edição, São Paulo: Quartier Latin, 2013.

BERCOVICI, Gilberto, Soberania econômica e regime jurídico do capital estrangeiro no Brasil, RBEC, Belo Horizonte, ano 5, n. 17, p. 95-110, jan/mar. 2011.

BONAVIDES, Paulo, Curso de Direito Constitucional, 22 a edição, São Paulo: Malheiros, 2008.

BORGES, Rodrigo Lanzi de Moraes, Os princípios na teoria dos direitos fundamentais de Robert Alexy, in Revista dos Tribunais, n. 182, São Paulo: Revista de Processo, p. 331-361, abril/2010. 
BRASIL, Advocacia-Geral da União, Parecer LA-01/2010, da lavra do Consultor-Geral da União, Dr. RONALDO JORGE ARAUJO VIEIRA JUNIOR. Disponível em http://www.agu.gov.br/atos/detalhe/258351, acesso em 05/04/2016.

BRASIL, Advocacia-Geral da União, Lei Complementar 76/93 comentada pela PFE/INCRA, Ano IV, n. 20 (ago/2012), Brasília: EAGU, 2012.

BRASIL, Exposição de motivos ao Decreto 4.887/2003, Disponível em http://www.planalto.gov.br/ccivil_03/Exm/2003/EMI58-CCV-MINC-MDA-SEPPIR$\underline{03 . h t m}$, acesso em 27/07/2017.

BRASIL, Instituto Nacional de Colonização e Reforma Agrária, Livro Branco da Grilagem de Terras, disponível em http://www.incra.gov.br/media/servicos/publicacao/livros_revistas_e_cartilhas/Livro\% 20Branco\%20da\%20Grilagem\%20de\%20Terras.pdf, acesso em 16 de junho de 2016.

BRASIL, Instituto Nacional de Colonização e Reforma Agrária, "Balanço da Gestão da PFE/INCRA de 2003/2010 \& Perspectivas - um compromisso com a reforma agrária”, Brasília: INCRA, 2010.

BRASIL, Instituto Nacional de Colonização e Reforma Agrária, Lei 8.629/93 comentada por procuradores federais, Brasília: INCRA, 2011.

BRASIL, Instituto Nacional de Colonização e Reforma Agrária, O INCRA e os desafios para a regularização dos territórios quilombolas - algumas experiências, Brasília: NEAD, 2006.

BRASIL, Ministério Público Federal, Regularização fundiária em unidades de conservação, Brasília: MPF, 2014.

BRASIL, Ministério Público Federal. 6 $6^{\mathrm{a}}$ Câmara de Coordenação e Revisão. Territórios de povos e comunidades tradicionais e as unidades de conservação de proteção integral: alternativas para o asseguramento de direitos socioambientais, Brasília: MPF, 2014, disponível em http://www.mpf.mp.br/atuacaotematica/ccr6/documentos-e-publicacoes/manual-de-atuacao/docs/manual-de-atuacaoterritorios-de-povos-e-comunidades-tradicionais-e-as-unidades-de-conservacao-deprotecao-integral, acesso em 19/07/2017.

CAMPOS, Francisco, "Poder de Emenda. Reforma Agrária", Bahia Forense, vol. $6, \mathrm{n}^{\circ} 5$, junho/dezembro de 1967 , pp. 24-35. 
CARVALHO, Josué Tomazi de; FIDELES, Junior Divino; MACIEL, Marcela Albuquerque, Direito Agrário, Salvador: Juspodivm, 2015.

CARVALHO, Vinicius Marques de, Regulação dos serviços de saneamento básico: cooperação institucional para o desenvolvimento do setor, in SALOMÃO FILHO, Calixto (org)., Regulação e desenvolvimento - novos temas, São Paulo: Malheiros, 2012, p.109-157.

CHACPE, Juliana Fernandes, Do conceito de imóvel rural como unidade de exploração econômica: consequências quanto à forma de elaboração de laudo agronômico de fiscalização e a classificação fundiária do imóvel para fins de desapropriação para reforma agrária, Disponível em: www.incra.gov.br, acesso em 16/03/2016.

CHIARA, José Tadeu de, Capitais estrangeiros, Revista de Direito Mercantil, Industrial, Econômico e Financeiro, São Paulo, n. 26, 1977.

Corte Interamericana de Direitos Humanos, sentença proferida em 29 de março de 2006, no caso da comunidade indígena Sawhoyamaxa versus Estado do Paraguai, Disponível em http://www.corteidh.or.cr/docs/casos/articulos/seriec_146_esp2.pdf, acesso em 02/08/2017.

COSTA, Emília Viotti da, Da Monarquia à República, 9a edição, $3^{\text {a }}$ reimpressão, São Paulo: Editora Unesp, 2010.

CRENSHAW, Kimberlé, Documento para o encontro de especialistas em aspectos da discriminação racial relativos ao gênero, disponível em http://www.scielo.br/pdf/ref/v10n1/11636.pdf, acesso em 25/07/2017.

CYSNEIROS, Vicente Cavalcanti, O estrangeiro e a propriedade rural, Porto Alegre: Sergio Antonio Fabris, 1985.

DALLARI, Dalmo de Abreu, Elementos de teoria geral do Estado, 13 ${ }^{\mathrm{a}}$ edição, São Paulo: Saraiva, 1987.

DINIZ, Maria Helena, Manual de Direito Civil, São Paulo: Saraiva, 2011.

DUARTE, Nestor, Reforma Agrária, Rio de Janeiro, Imprensa Nacional, 1953. 
DUPRAT, Deborah, A Convenção n. 169 da OIT e o direito à consulta prévia, livre e informada in DUPRAT, Deborah (organizadora), Convenção n. 169 da OIT e os Estados Nacionais, Brasília: ESMPU, 2015, p. 53-78.

DUPRAT, Deborah, O Estado Pluriétnico, disponível em http://www.mpf.mp.br/atuacao-tematica/ccr6/documentos-e-

publicacoes/artigos/docs/artigos/docs_artigos/estado_plurietnico.pdf, acesso em 21/07/2017.

DUPRAT, Deborah, O Direito sob o marco da plurietnicidade/multiculturalidade, disponível em http://www.mpf.mp.br/atuacaotematica/ccr6/documentos-e-publicacoes/artigos/docs/artigos/documentos-epublicacoes/artigos/docs_artigos/o_direito_sob_o_marco_da_plurietnicidade_multicult uralidade.pdf, acesso em 21/07/2017.

ESTERCI, Neide, Amazônia: Povos tradicionais e luta por direitos, in BOTELHO, André e SCHWARCZ, Lilia Moritz (Organizadores), Cidadania, um projeto em construção: minorias, justiça e direitos, São Paulo: Claroenigma, 2012.

FACHIN, Luiz Edson, Conceituação do direito de propriedade in Doutrinas Essenciais de Direitos Humanos, vol. 2, DTR\2012\681, Revista dos Tribunais, São Paulo, agosto de 2011, p.813-852.

FACHIN, Luiz Edson, et al., Reforma agrária e constituinte, disponível em https://dspace.almg.gov.br/bitstream/11037/1630/3/1630.pdf , acesso em 28/04/2016.

FACHIN, Luiz Edson, Reflexões sobre os rumos da reforma agrária no Brasil in Revista de Informação Legislativa, a. 24, n. 96, Brasília, out/dez. 1987, disponível em http://www2.senado.leg.br/bdsf/bitstream/handle/id/181818/000434362.pdf?sequence= 1, acesso em 02/05/2016.

FARENA, Duciran Van Marsen, Aspectos polêmicos acerca da criação e implantação de unidades de conservação, Boletim Científico, a. 6, n. 24/25, p. 123-150, Brasília: ESMPU, julho/dezembro 2007.

FAUSTO, Bóris, História concisa do Brasil, São Paulo: Edusp, 2010. 
FERREIRA FILHO, Paulo Sérgio, Ministério Público e a Regularização Fundiária Urbana em Áreas de Preservação Permanente, Rio de Janeiro: Lumen Juris, 2017.

FIDELES, Junior Divino, A justa indenização nas desapropriações agrárias e como se formam as superindenizações, Dissertação de mestrado apresentada à Universidade Federal de Goiás, Goiania: 2014. Disponível em https://repositorio.bc.ufg.br/tede/bitstream/tede/4155/5/Disserta\%C3\%A7\%C3\%A3o\% 20-\%20Junior\%20Divino\%20Fidelis\%20-\%202014.pdf, acesso em 28/04/2016.

FILIPPI, Eduardo Ernesto, Reforma Agrária: experiências internacionais de reordenamento agrário e a evolução da questão da terra no Brasil, Porto Alegre: UFRGS, 2005.

FONSECA, Ricardo Almeida, A Lei de Terras e o advento da propriedade $\begin{array}{llll}\text { moderna no } & \text { Brasil, em }\end{array}$ http://www.juridicas.unam.mx/publica/librev/rev/hisder/cont/17/cnt/cnt5.pdf, acesso em 17/06/2016.

GAGLIANO, Pablo Stolze, PAMPLONA FILHO, Rodolfo, Novo curso de Direito Civil, Parte Geral, 12a edição, v.1, Saraiva: São Paulo, 2010.

GONÇALVES, Carlos Roberto, Direito Civil Brasileiro, $8^{a}$ edição, Saraiva: São Paulo, 2010.

GONÇALVES, Carlos Roberto, Direito das obrigações, Parte especial, Tomo I- contratos, 6a edição, São Paulo: Saraiva, 2002 (Coleção sinopses jurídicas).

GUADANHIN, Gustavo de Carvalho, A permanência de comunidades tradicionais em unidades de conservação de proteção integral, Revista dos Tribunais, vol. 913/2011, p. 59-80, Nov/2011.

GRAU, Eros, A ordem econômica na Constituição de 1988, $16^{\text {a }}$ edição, Editora Malheiros: São Paulo, 2014.

GRAU, Eros, A ordem econômica na Constituição de 1988, 17ª edição, Editora Malheiros: São Paulo, 2015.

GUGLIELMI, Vito José, As terras devolutas e seu registro in Revista de Direito Imobiliário, vol. 29/1992, São Paulo, p.86-114, jan-junho/1992. 
HAVRENNE, Michel F. D. , A aquisição de imóveis rurais por estrangeiros no Brasil in Revista dos Tribunais, São Paulo, v. 919, p. 85-108, 2012.

HAVRENNE, Michel F. D., A compra e venda como meio de implementação da reforma agrária no Brasil in Revista dos Tribunais, São Paulo, vol. 949/2014, p. 71, novembro de 2014.

HAVRENNE, Michel F. D., Regularização fundiária na Amazônia, Jornal Valor Econômico, Seção Opinião Jurídica, 28/07/2017.

HECK, Mariana, O princípio da precaução em Direito Internacional do Meio Ambiente, in Boletim Científico, a. II, no 9, Brasília: ESMPU, out/dez. 2003, p. 113137, disponível em http://escola.mpu.mp.br/publicacoes/boletim-cientifico/edicoes-doboletim/boletim-cientifico-n-9-outubro-dezembro-de-2003/o-principio-da-precaucaoem-direito-internacional-do-meio-ambiente, acesso em 16/07/2017.

HIDALGO, Telmo, Reforma Agraria, Ideología y Política, Quito: Ediciones La Tierra, 2010.

HOLANDA, Sérgio Buarque de, Raízes do Brasil, 26 edição, 34 reimpressão, São Paulo: Companhia das Letras, 1995.

IRTI, Natalino, L'ordine giuridico del mercato, $4^{\text {a }}$ edizione, Bari: Laterza, 2001.

JULIÃO, Francisco, "O ABC do Camponês" e outros textos das Ligas Camponesas in STEDILE, João Pedro (org.), A questão agrária no Brasil- História e natureza das Ligas Camponesas - 1954-1964, São Paulo: Expressão Popular, 2006.

LIMA, Oliveira, Formação histórica da nacionalidade brasileira, $3^{\mathrm{a}}$ edição, Rio de Janeiro: Toopbooks; São Paulo: Publifolha, 2000 (Grandes nomes do pensamento brasileiro).

LIMA, Ruy Cirne, Terras devolutas (História, Doutrina, Legislação), Porto Alegre: Livraria do Globo, 1935.

LIMA, Ruy Cirne, Pequena História Territorial do Brasil. Sesmarias e Terras Devolutas, São Paulo: Arquivo do Estado de São Paulo, 1991.

LUÑO, Antonio Enrique Pérez, Derechos humanos, estado de derecho y Constitución, 10ª edição, Madrid: Tecnos, 2010. 
MARQUES, Benedito Ferreira, Direito Agrário Brasileiro, Atlas: São Paulo, 2009.

MARTINS, José de Souza, Reforma agrária - o impossível diálogo sobre a História possível, disponível em www.revistas.usp.br, Acesso em 04/12/2014.

MASCARO, Alysson Leandro, Para uma teoria geral da segurança jurídica. Revista Brasileira de Estudos Constitucionais - RBEC, Belo Horizonte, ano 9, n. 31, jan/abr. 2015. Disponível em: <http://www.bidforum.com.br/PDI0006.aspx?pdiCntd=236918>. Acesso em: 9 abr. 2017.

MATTOS NETO, Antonio José de, Estado de Direito Agroambiental brasileiro, São Paulo: Saraiva, 2010.

MAZZILLI, Hugo Nigro, A defesa dos interesses difusos em juízo, 17ª edição, São Paulo: Saraiva, 2004.

MEIRELLES, Hely Lopes, Direito Administrativo Brasileiro, 30 edição, atualizada por Eurico de Andrade Azevedo, Délcio Balestero Aleixo e José Emmanuel Burle Filho, São Paulo: Malheiros, 2005.

MELO, Cristina Nascimento de e BIJOS, Leila, Demarcação de terras indígenas e sistema interamericano de direitos humanos: a responsabilidade do Estado por ato judicial, in Revista Brasileira de Direito Internacional, Curitiba, v. 2, n.2, p. 2338, jul/dez. 2016.

MELO, Mônica de, Plebiscito, Referendo e iniciativa popular - mecanismos constitucionais de participação popular, Porto Alegre: Sérgio Antonio Fabris Editor, 2001.

MELO, Tarso de, Direito e Ideologia: um estudo a partir da função social da propriedade rural, $2^{\mathrm{a}}$ edição, São Paulo: Outras expressões, Dobra Editorial, 2012.

MENDES, Gilmar Ferreira, A reforma do sistema judiciário no Brasil: elemento fundamental para garantir segurança jurídica ao investimento estrangeiro no Brasil, Doutrinas essenciais de direito empresarial, vol. 8, p. 771-777, dez/2010, DTR\2009\888. 
MENDES, Gilmar Ferreira, COELHO, Inocêncio Mártires e BRANCO, Paulo Gustavo Gonet, Curso de Direito Constitucional, $2^{a}$ edição, São Paulo: Saraiva, 2008.

MOREIRA, Igor, O espaço geográfico, Geografia geral e do Brasil, São Paulo: Ática, 1990.

NAKAMURA, André Luiz dos Santos. Doação de bens imóveis pela Administração Pública. Fórum Administrativo - FA, Belo Horizonte, ano 14, n. 159, maio 2014. Disponível em: <http://www.bidforum.com.br/PDI0006.aspx?pdiCntd=117666>. Acesso em: 11 abr. 2017.

NASCIMENTO, Tupinambá Miguel Castro do, Introdução ao Direito Fundiário, Porto Alegre: Sergio Antonio Fabris Editor, 1985.

NOLTE, Christoph, AGRAWAL, Arun e BARRETO, Paulo, Setting priorities to avoid deforestation in Amazon protected areas: are we choosing the right indicators?, disponível em http://iopscience.iop.org/article/10.1088/17489326/8/1/015039;jsessionid=ADA8C3F649506FE5844BB6488789371E.c1.iopscience. cld.iop.org, acesso em 17/06/2016.

OLIVEIRA, Ludmila Junqueira Duarte, Regularização fundiária de unidades de conservação, Boletim Científico, Brasília: ESMPU, a. 9, n.32/33, p. 143-176, jan./dez. 2010.

OLIVEIRA, Umberto Machado de, Princípios de direito agrário na Constituição vigente, $1^{\mathrm{a}}$ edição, $4^{\mathrm{a}}$ reimpressão, Curitiba: Juruá, 2010.

OPITZ, Silvia C. B. e OPITZ, Oswaldo, Curso completo de direito agrário, $2^{\text {a }}$ edição, Saraiva: São Paulo, 2007.

PEREIRA, Osny Duarte, Que é a Constituição? Crítica à Carta de 1946 com vistas a Reformas de Base, Rio de Janeiro, Civilização Brasileira, 1964.

PIETRO, Maria Sylvia Zanella, Direito Administrativo, 10a edição, São Paulo: Atlas, 1998.

PINTO JÚNIOR, Joaquim Modesto, FARIAS, Valdez Adriani, Função social da propriedade: dimensões ambiental e trabalhista, Brasília: Núcleo de Estudos Agrários e Desenvolvimento Rural, 2005. 
PRIEUR, Michel, Mondialisation et droit de l'environnement, in Meio Ambiente, série Grandes Eventos, volume I, Brasília: ESMPU, Disponível em http://escola.mpu.mp.br/publicacoes/obras-avulsas/e-books/grandes-eventos, acesso em 16/07/2017.

ROCHA, Ibraim, TRECCANI, Girolamo Domenico, BENATTI, José Heder, HABER, Lilian Mendes, CHAVES, Rogério Arthur Friza Chaves, Manual de Direito Agrário Constitucional, Fórum: Belo Horizonte, 2010.

ROCHA, Ibraim, TRECCANI, Girolamo Domenico, BENATTI, José Heder, HABER, Lilian Mendes, CHAVES, Rogério Arthur Friza Chaves, Manual de Direito Agrário Constitucional, 2a edição, Fórum: Belo Horizonte, 2010.

ROCHA, Olavo Acyr de Lima, O imóvel rural e o estrangeiro, São Paulo: LTR, 1999.

ROTHENBURG, Walter Claudius, Direitos dos descendentes de escravos (remanescentes das comunidades de quilombos), p. 446-471 in SARMENTO, Daniel; IKAWA, Daniela; PIOVESAN, Flávia (Coords.), Igualdade, Diferença e Direitos Humanos, Rio de Janeiro: Lumen Juris, 2008.

SAMPAIO, Plínio de Arruda, A questão agrária brasileira e a luta pelo socialismo, disponível em http://coral.ufsm.br/enev/docs/questaoagraria.pdf, acesso em 10/05/2016.

SAMPAIO, Plínio de Arruda, As duas novas reformas agrárias, disponível em https://www.ecodebate.com.br/2009/12/07/as-duas-novas-reformas-agrarias-artigo-deplinio-de-arruda-sampaio/, acesso em 10/05/2016.

SANTOS, Mauro Sérgio dos, Curso de Direito Administrativo, Rio de Janeiro: Forense, 2012.

SÃO PAULO, ITESP, Terra e Cidadãos: Aspectos da ação de regularização fundiária no Estado de São Paulo, no 4 (Nov. 1998), São Paulo: ITESP, 1998.

SARMENTO, Daniel, Territórios Quilombolas e Constituição: A ADI 3.239 e a Constitucionalidade do Decreto 4.887/03, disponível em http://www.mpf.mp.br/atuacao-tematica/ccr6/documentos-epublicacoes/artigos/docs/artigos/docs_artigos/Territorios_Quilombolas_e_Constituicao _Dr._Daniel_Sarmento.pdf, acesso em 21/07/2017. 
SEGER, Franciele e HAVRENNE, Michel François Drizul, O desafio do desenvolvimento sustentável: em busca de um 'mercado verde' por meio da tributação ambiental in Revista Direito e Sociedade, v.1, p. 153-168, 2013. Disponível em www.fema.com.br, acesso em 14/02/2016.

SILVA, Angela, Terras Devolutas in Revista de Direito Imobiliário, vol. 14/1984, São Paulo, p. 42-82, jul-dez/1984.

SILVA, José Afonso da, Aplicabilidade das normas constitucionais, $6^{a}$ edição, $2^{a}$ tiragem, São Paulo: Malheiros, 2003.

SILVA, José Afonso da, Direito Ambiental Constitucional, $4^{\mathrm{a}}$ edição, $2^{\mathrm{a}}$ tiragem, São Paulo: Malheiros, 2003.

SILVA, José Afonso da, Curso de Direito Constitucional Positivo, 20a edição, São Paulo: Malheiros, 2002.

SILVA, Jose Afonso da, Parecer jurídico, Disponível em http://www.mpf.mp.br/atuacao-tematica/ccr6/documentos-e-

publicacoes/artigos/docs_artigos/jose-afonso-da-silva-parecer-maio-2016-1.pdf, acesso em 01/08/2017.

SILVA, José Gomes da, A reforma agrária na virada do milênio, $2^{\mathrm{a}}$ edição, Maceio: EDUFAL, 1997.

SILVA, José Graziano da, A reforma agrária no Brasil in STÉDILE, João Pedro, A questão agrária no Brasil: o debate na década de 1990, São Paulo: Expressão Popular, 2013.

SILVA, José Graziano da, O que é questão agrária, Coleção Primeiros Passos, 14 edição, São Paulo: Brasiliense, 1987.

SILVA, Lígia Osorio, Terras devolutas e latifúndio. Efeitos da lei de 1850, Campinas: Editora da Unicamp, 1996.

SMITH, Roberto, Propriedade da terra e transição. Estudo da formação da propriedade privada da terra e transição para o capitalismo no Brasil, $2^{a}$ edição, São Paulo: Brasiliense, 2008.

STROZAKE, Juvelino José (org.), A questão agrária e a justiça, São Paulo: Editora Revista dos Tribunais, 2000. 
TAVARES, André Ramos, Curso de Direito Constitucional, 13ª edição, Saraiva: São Paulo, 2015.

TELLES JUNIOR, Goffredo, $2^{\mathrm{a}}$ edição, O povo e o poder, São Paulo: Juarez de Oliveira, 2006.

VEIGA, José Eli da, Reforma agrária hoje in STÉDILE, João Pedro, A questão agrária no Brasil: o debate na década de 1990, São Paulo: Expressão Popular, 2013.

VEIGA, José Eli da, O que é reforma agrária, 13ª edição, Coleção Primeiros Passos, São Paulo: Brasiliense, 1990.

VENOSA, Sílvio de Salvo, Direito Civil: direitos reais, $5^{a}$ edição, São Paulo: Atlas, 2005.

VITORELLI, Edilson, Estatuto da Igualdade Racial e Comunidades Quilombolas, 2a edição, Salvador: Juspodivm, 2015.

VITORELLI, Edilson, Estatuto do Índio, Salvador: Juspodivm, 2011.

\section{Sites consultados}

www.agu.gov.br

www.almg.gov.br

www.camara.leg.br

www.conjur.com.br

www.ecodebate.com.br

www.fema.com.br

www.folha.com.br

www.incra.gov.br

www.mpf.mp.br

www.painelflorestal.com.br

www.senado.leg.br 
www.stf.jus.br

www.stj.jus.br

www.ufsm.br

www.usp.br

https://pt.wikipedia.org/wiki 


\section{Anexo - Projeto de Lei $n^{\circ} 8.411 / 2017$}

\section{PROJETO DE LEI No , DE 2017 \\ (Do Sr. CARLOS BEZERRA)}

Altera os arts. 6, 15, 16 e 18 da Lei 11.952, de 25 de junho de 2009.

O Congresso Nacional decreta:

Art. $1^{\circ} \mathrm{O}$ art. $6^{\circ}, \S 1^{\circ}$, da Lei 11.952 , de 25 de junho de 2009 , passa a vigorar com a seguinte redação:

Art. $6^{\circ}$ $\S 1^{\circ}$ Serão regularizadas as ocupações de áreas não superiores a 1.500ha (mil e quinhentos hectares).

Art. $2^{\circ} \mathrm{O}$ art. 15 da Lei 11.952 , de 25 de junho de 2009 , passa a vigorar com a seguinte redação:

Art. 15. O título de domínio ou, no caso previsto no $\S 4^{\circ}$ do art. $6^{\circ}$, o termo de concessão de direito real de uso, deverá conter, entre outras, cláusulas sob condição resolutiva pelo prazo de 10 (dez) anos, que determinem:

I - a manutenção da destinação agrária, por meio de prática de cultura efetiva;

II - a averbação da reserva legal, incluída a possibilidade de compensação na forma de legislação ambiental; 
III - a identificação das áreas de preservação permanente e, quando couber, o compromisso para sua recuperação na forma da legislação vigente;

IV - a não exploração de mão de obra em condição análoga à de escravo; $\mathrm{e}$

$\mathrm{V}$ - as condições e forma de pagamento.

Art. $3^{\circ} \mathrm{O}$ art. 16 da Lei 11.952 , de 25 de junho de 2009, passa a vigorar com a seguinte redação:

Art. 16. As condições resolutivas do título de domínio e do termo de concessão de uso somente serão liberadas após vistoria.

Art. $4^{\circ} \mathrm{O}$ art. 18 Lei 11.952 , de 25 de junho de 2009, passa a vigorar com a seguinte redação:

Art. 18. O descumprimento das condições resolutivas pelo titulado implica resolução de pleno direito do título de domínio ou do termo de concessão, declarada no processo administrativo que apurar o descumprimento das cláusulas resolutivas, assegurados os princípios da ampla defesa e do contraditório.

$\S 1^{\circ} \mathrm{O}$ desmatamento que vier a ser considerado irregular em áreas de preservação permanente ou de reserva legal implica resolução do título de domínio ou do termo de concessão, com a consequente reversão da área em favor da União.

$\S 2^{\circ}$ Resolvido o título de domínio ou o termo de concessão na forma do caput deste artigo, o contratante:

I - terá direito à indenização pelas acessões e pelas benfeitorias, necessárias e úteis, podendo levantar as voluptuárias no prazo máximo de cento e oitenta dias após a desocupação do imóvel, sob pena de perda delas em proveito do alienante;

II - terá direito à restituição dos valores pagos com a devida atualização monetária, deduzido o percentual das quantias abaixo: a) 15\% (quinze por cento) do valor pago a título de multa compensatória; e b) $0,3 \%$ (três décimos por cento) do valor atualizado do contrato por cada mês de ocupação do imóvel desde o início do contrato, a título de indenização pela fruição; 
III - estará desobrigado de pagar eventual saldo devedor remanescente na hipótese de o montante das quantias indicadas nas alíneas a e b do inciso II deste parágrafo eventualmente exceder ao valor total pago a título de preço.

$3^{\circ}$ A critério da administração pública federal, exclusivamente em casos de interesse social na destinação da área, havendo desocupação voluntária, o ocupante poderá receber compensação financeira pelas benfeitorias úteis ou necessárias edificadas até a data de notificação da decisão que declarou a resolução do título de domínio ou da concessão.

$\S 4^{\circ}$ Ato do Poder Executivo disporá sobre regulamento para disciplinar o valor e o limite da compensação financeira, além de estabelecer os prazos para pagamento e para a desocupação prevista no $\S 2^{\circ}$ deste artigo. $\S 5^{\circ} \mathrm{Na}$ hipótese de a área titulada passar a integrar a zona urbana ou de expansão urbana, deverá ser priorizada a análise do requerimento de liberação das condições resolutivas.

Art. $5^{\circ}$ Esta lei entra em vigor na data de sua publicação.

\section{JUSTIFICAÇÃO}

No dia 28 de julho de 2017, o periódico Valor Econômico publicou um artigo no qual o Procurador da República Michel François Drizul Havrenne tece pertinentes críticas às alterações trazidas na Lei 11.952/09 pela Lei 13465/17, resultante da tramitação da Medida Provisória 759/16.

Com essa perspectiva, reconhecendo a importância da regularização fundiária, na busca pelo cumprimento da Constituição Federal, principalmente no que se refere à justiça social e agrária, o autor sugere algumas modificações normativas, as quais buscamos consubstanciar neste Projeto de Lei. Em suas próprias palavras:

"Recentemente, a Lei 11.952/09 sofreu inúmeras alterações pela Medida Provisória no 759/16. Esta, por sua vez, foi convertida na Lei 13.465, de 11 de julho de 2017. 
Um dos pontos críticos da nova lei refere-se à flexibilização da proteção ambiental, haja vista que, em diversos dispositivos, permite àquele que realizou infrações ambientais ser regularizado.

Veja-se que ela substituiu as condições resolutivas que previam a necessidade de averbação da reserva legal e de compensação ambiental, de identificação das áreas de preservação permanente e do compromisso de sua recuperação (art. 15, II e III, da redação antiga) pela cláusula genérica de respeito à legislação ambiental, em especial, o cumprimento do Cadastro Ambiental Rural (art. 15,II).

Na prática, a comprovação dos requisitos ambientais será circunscrita ao CAR, que é um ato meramente declaratório.

Tal flexibilização exagerada vai contra os objetivos da regularização fundiária, já que ela é indissociavelmente atrelada ao combate do desmatamento na Amazônia.

Não se pode, pois, inserir dispositivos que permitam danos ambientais, seja em função da omissão de fiscalização dos entes ambientais, seja em virtude de interesses ilegítimos, como os dos grileiros.

Ainda, a nova lei contém algumas falhas na proteção ambiental, como a possibilidade de concessão de título de domínio, por mera análise documental, sem qualquer vistoria do cumprimento da função ambiental do imóvel (art. 16).

Também, há possibilidade de regularização de imóvel rural, em caso de desmatamento, se este ocorrer após o prazo de dez anos das condições resolutivas, ou não existir prova de que ele ocorreu durante a vigência das condições resolutivas (art. 18).

Outro ponto que merece críticas vincula-se à ampliação da área suscetível de regularização fundiária, de 1.500 hectares para 2.500 hectares. Esta mudança não se compatibiliza com o programa de regularização fundiária rural, haja vista que ele visa erradicar a pobreza e as desigualdades sociais, devendo ser utilizado como instrumento de ascensão social, e não de perpetuação da concentração de renda." ${ }^{429}$

\footnotetext{
${ }^{429}$ HAVRENNE, Michel François Drizul: Regularização Fundiária na Amazônia. Valor Econômico, sexta feira, 28 de julho de 2017, Caderno Legislação e Tributos, p. E2.
} 
Isso posto, atento à opinião da comunidade científica especializada, apresentamos a proposta para que se retifique alguns pontos na regularização fundiária da Amazônia Legal, na busca por um desenvolvimento social sem que se deixe de lado os aspectos ecológicos.

Sala das Sessões, em de de 2017.

Deputado CARLOS BEZERRA 